\title{
Examining the construct validity of the Basic Traits Inventory and the Ten-Item Personality Inventory in the South African context
}

\begin{tabular}{|c|c|}
\hline \multicolumn{2}{|c|}{$\begin{array}{l}\text { Authors: } \\
\text { Samantha A. Metzer } \\
\text { Gideon P. de Bruin } \\
\text { Byron G. Adams }{ }^{1}\end{array}$} \\
\hline $\begin{array}{l}\text { Affiliations: } \\
{ }^{1} \text { Department } \\
\text { Psychology an } \\
\text { Management, } \\
\text { Johannesburg }\end{array}$ & $\begin{array}{l}\text { f Industrial } \\
\text { People } \\
\text { University of } \\
\text { South Africa }\end{array}$ \\
\hline $\begin{array}{l}\text { Corresponden } \\
\text { Byron Adams }\end{array}$ & ce to: \\
\hline $\begin{array}{l}\text { Email: } \\
\text { bgadams@uj.c }\end{array}$ & \\
\hline $\begin{array}{l}\text { Postal address } \\
\text { PO Box 524, A } \\
\text { 2006, South A }\end{array}$ & $\begin{array}{l}\text { uckland Park } \\
\text { rica }\end{array}$ \\
\hline $\begin{array}{l}\text { Dates: } \\
\text { Received: } 25 \mathrm{~J} \\
\text { Accepted: } 01 \mathrm{I} \\
\text { Published: } 27\end{array}$ & $\begin{array}{l}\text { lly } 2011 \\
\text { eb. } 2014 \\
\text { Aug. } 2014\end{array}$ \\
\hline $\begin{array}{l}\text { How to cite th } \\
\text { Metzer, S.A., } \\
\text { G.P., \& Adams } \\
\text { Examining the } \\
\text { validity of the } \\
\text { Inventory and } \\
\text { Personality Inv } \\
\text { the South Afri } \\
\text { SA Journal of I } \\
\text { Psychology/SA } \\
\text { Bedryfsielkun } \\
\text { \#1005, } 9 \text { page } \\
\text { dx.doi.org/10. } \\
\text { v40i1.1005 }\end{array}$ & $\begin{array}{l}\text { is articl: } \\
\text { e Bruin, } \\
\text { B.G. (2014). } \\
\text { construct } \\
\text { Basic Traits } \\
\text { the Ten-Item } \\
\text { entory in } \\
\text { an context. } \\
\text { 1dustrial } \\
\text { Tydskrif vir } \\
\text { e, 40(1), Art. } \\
\text { http:// } \\
4102 / \text { sajip. }\end{array}$ \\
\hline $\begin{array}{l}\text { Copyright: } \\
\text { (C) 2014. The A } \\
\text { Licensee: AOS } \\
\text { OpenJournals. } \\
\text { is licensed unc } \\
\text { Creative Comn } \\
\text { Attribution Lic }\end{array}$ & $\begin{array}{l}\text { uthors. } \\
\text { S } \\
\text { This work } \\
\text { er the } \\
\text { tons } \\
\text { ense. }\end{array}$ \\
\hline 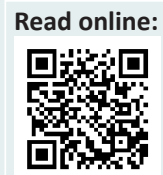 & $\begin{array}{l}\text { Scan this QR } \\
\text { code with your } \\
\text { smart phone or } \\
\text { mobile device } \\
\text { to read online. }\end{array}$ \\
\hline
\end{tabular}

\section{Authors:}

Affiliations:

Psychology and People

Management, University of

Correspondence to

Email:

PO Box 524, Auckland Park

Dates:

Accepted: 01 Feb 2014

How to cite this articl

etzer, S.A., De Bruin,

Examining the construct

validity of the Basic Traits

Inventory and the Ten-Item

Personality Inventory in

SA Journal of Industrial

Psychology/SA Tydskrif vir

Bedryfsielkunde, 40(1), Art.

.4102/sajip.

Copyright:

2014. The Authors.

OpenJournals. This work

is licensed under the

Creative Commons

Attribution License.
Orientation: As there has recently been a need for researchers to consider shorter personality measures, we compared the construct validity of a longer and a shorter personality measure in the South African context.

Research purpose: The main purpose of this study was to examine the discriminant and convergent validity of two personality measures that measure the big five personality factors: the longer Basic Traits Inventory (BTI) and the shorter Ten-Item Personality Inventory (TIPI).

Motivation for the study: Researchers have indicated a need for shorter personality measures, such as the TIPI, to assess personality dimensions. This study assessed the validity of the shorter measure in comparison with the BTI, which is considered cross-culturally valid in the South African context.

Research approach, design and method: This study used a quantitative research design. Both personality measures were administered manually to a convenience sample of student participants $(n=662)$, and data were analysed through factor analysis utilising oblique rotation for all items.

Main findings: The main findings indicate that, although the construct validity of both measures was satisfactory, the TIPI yielded unsatisfactory reliability.

Practical/managerial implications: The BTI is a more reliable measure than the TIPI, which should only be used when time is limited.

Contribution/value-add: In addition to providing insight into how the length of an assessment impacts on the reliability of a measure, this study further reinforces the use of the basic traits inventory as a measure that reliably measures personality in South Africa.

\section{Introduction}

Personality measures are considered important for making decisions regarding individuals. They are used to understand why humans behave and think as they do by identifying the unique set of traits, characteristics or attitudes of a person, understanding a person's performance potential and possibly their career interest (Costa, 2008; Salkind, 2006; Tett \& Burnett, 2003). In this study we examine how the length of a personality measure impacts on the measure's construct validity. Most personality measures are often considered long, and, particularly in research settings (Gosling, Rentfrow, \& Swann, 2003), candidates may experience fatigue, frustration and confusion (Saucier, 1994) whilst completing them. In South Africa, in addition to the fatigue, frustration and confusion candidates may face, there is also the question of the diverse South African population (Meiring, Van de Vijver, Rothmann \& Barrick, 2005). Here there are considerations of culture, language and socio-economic status which may impact individuals' responses and that may result in candidates not answering questions accurately or the inaccurate interpretation of individual results. Therefore, the impact of the length of a measure may provide additional insight into the psychometric properties of personality measures in South Africa.

In South Africa, the use of psychological assessment is governed by the Employment Equity Act (Act No. 55 of 1998), which states that:

psychological testing and other similar assessments are prohibited unless the test or assessment being used (a) has been scientifically shown to be valid and reliable, (b) can be applied fairly to all employees, and (c) is not biased against any employee or group. (Republic of South Africa, 1998, p. 9)

The onus is therefore on the psychologist to acquire and utilise knowledge that will allow them to develop shorter personality measures from which more rapid decisions can be made 
in comparison with longer personality questionnaires (Van Eeden, Cilliers \& Van Deventer, 2008). However, irrespective of its length, a personality measure requires a demonstration of satisfactory psychometric properties in line with South African legislation (Meiring et al., 2005). According to Friedenberg (1995), an effective test displays three important psychometric properties: firstly, the test is valid, secondly, the test is reliable and, thirdly, it contains items that have valid item statistics.

It is widely accepted that long questionnaires have better psychometric properties than short questionnaires (Gosling et al., 2003). Most test administrators today would be very concerned if a test consisted of only a few items. A study by Burisch (1997) shows that the psychometric advantages of a long test is not always what one would expect. He compared subsets of two relatively short depression scales (nine and eight items respectively) with much longer ones (50 and 28 items respectively). The selected scale subsets were based on their content, and in 10 out of the 19 cases the selected subsets performed psychometrically better than the longer measures; in other words, curtailing scales enhanced rather than attenuated their validity. Burisch (1997) suggests that when a test is being developed, it is not necessarily the number of items included that is important, but rather the quality of the item definitions in measuring a specific construct.

However, there are also several limitations of using shorter personality measures. In the study by Gosling et al. (2003) three limitations were identified. Firstly, there was a decrease in the reliability properties compared to longer questionnaires with standard multi-item measures. Secondly, the short questionnaire was less reliable, converged less strongly with the big five personality measure and had weaker correlations with other variables. Thirdly, the individual facets of multifaceted constructs are not always measured accurately, and therefore a longer personality questionnaire is preferable.

\section{The Five-Factor Trait Model}

The Five-Factor Trait Model (FFM) is currently the most popular model of personality trait factors and has served as a foundation for personality measures (Muck, Hell \& Gosling, 2007; Woods \& Hampson, 2005). It has been described as a 'Christmas tree on which findings of stability, heritability, consensual validation, cross-cultural invariance, and predictive utility are hung like ornaments' (Pervin \& John, 1999, p. 139). To illustrate all these ornaments of personality systematically and to lessen the confusion of the role of traits in personality, a five-factor personality system was designed. This model is the basis of the five-factor theory that explains how personality operates from a trait perspective. It provides a framework for the functioning of a person over a complete life span (Pervin \& John, 1999). Anastasi and Urbina (1997, p. 506) state that the popularity of the FFM in personnel selection research is not coincidental'.

The FFM summarises personality into five broad theoretically and operationally defined dimensions, namely Neuroticism,
Extroversion, Openness to Experience, Agreeableness and Conscientiousness. Neuroticism indicates how calm and self-confident an individual is, as opposed to being insecure and anxious. Extroversion measures how confident, social and assertive a person is, or, conversely, how introverted (withdrawn, quiet and reserved). Openness to Experience measures the extent to which an individual is imaginative and curious, as opposed to being closed minded and narrow thinking. Agreeableness indicates whether an individual is more warm and cooperative than unpleasant and disagreeable. Finally, Conscientiousness is the degree to which a person is organised and responsible, as opposed to being impulsive and irresponsible (Hofmans, Kuppens \& Allik, 2008; Pervin \& John, 1999).

Since its development, the FFM has been extensively revised over the past five decades (Rothman \& Coetzer, 2002). These revisions, plus an accumulation of information in support of the model, means that the construct validation of these traits is now more securely established than before. This is undoubtedly why the five-factor trait model has captured so much interest and been the foundation for the development of personality questionnaires such as the Basic Traits Inventory (BTI) and the Ten-Item Personality Inventory (TIPI).

\section{Basic Traits Inventory}

The BTI was developed by Taylor and De Bruin (2006) to assess personality in line with the FFM (Laher, 2007; McCrae \& Allik, 2002; Pervin \& John, 1999) across cultures in South Africa. According to Taylor (2004), some of the personality testing conducted in South Africa is based on personality questionnaires from other countries. The most common and widely known are the 16 Personality Factor Inventory (16PF) and the Myers-Briggs Type Indicator ${ }^{\circledR}\left(\mathrm{MBTI}^{\circledR}\right)$. Although some of these questionnaires have been revised for use in South Africa, there is still a concern that certain population groups are not adequately represented. There were no appropriate personality questionnaires for a multicultural South Africa when the BTI was developed, and so the subsequent aim was to develop a questionnaire that could be used for members of all cultures within the South African population with at least a Grade 12 level of education. Research has shown that the five personality factors in the BTI can be extracted across the diverse cultures in South Africa, although further research needs to be performed to determine if the five factors constitute a comprehensive representation of a personality within the South African context (Meiring et al., 2005).

There are many characteristics that distinguish this questionnaire as a long personality questionnaire, with the most obvious being that it takes at least 45 minutes to complete. Many items were included in the questionnaire to specifically ensure that the questionnaire could be applied cross-culturally and to reduce bias against any race, gender or language groups in South Africa. Unlike some other personality questionnaires, the items are written in a positive manner and words like 'never', 'not', or 'no' 
were not used in the construction of the items (Taylor, 2004). According to Taylor (2004), items that are worded negatively or are negatively keyed can cause conceptual confusion. Therefore, wording the items in a positive manner produces less confusion and enables respondents to quickly recognise and understand the word or a statement. To ensure the cross-cultural suitability of the BTI, all items were screened for appropriateness with regard to content and comprehensibility. They are presented in blocks, there are no reverse scored items and the response categories of the fivepoint Likert scale are clearly labelled.

Another characteristic of this long personality questionnaire is that it includes factors and facets that provide a broader view of the five personality factors. The BTI consists of five factors and underlying facets. The factors included in this inventory are: Openness to Experience, Conscientiousness, Extroversion, Agreeableness and Neuroticism. The five factors are subdivided into five facets, except for Neuroticism, which has four facets. In addition, the BTI includes a measure of social desirability. Some of the facet scales in the NEO PI-R were included in this questionnaire, as the NEO PI-R is also structured around factors and facets. In addition, due to an extensive literature review by Taylor (2004), some new scales were included in the BTI not included in the NEO PI-R.

According to Taylor and De Bruin (2006), the BTI is an easyto-use and easy-to-understand personality inventory. No psychological terminology is used in the questionnaire and the language is what most people would use in everyday life. The items are as short as possible so as to be clearly understandable. The BTI can be used for recruitment and selection purposes, staff development, educational settings, psychodiagnostics, counselling and research.

\section{Ten-Item Personality Inventory}

There have been several studies conducted using the TIPI, and this has resulted in the positive measurements of the big five personality factors. One such study was conducted by Gosling et al. (2003). It evaluated how the TIPI measures the big five personality factors and its convergence with a more established questionnaire, the Big Five Inventory (BFI). Three tests were used to evaluate the TIPI against the BFI. The first was to assess the convergent and discriminate validity by obtaining self-ratings for both questionnaires. In the second test, the test-retest reliability was measured, which involved students taking a revised version of the tenitem test six weeks after the first administration. Lastly, the patterns of external correlates were examined by obtaining self-ratings on several other measures. The results of the studies suggested that, although the TIPI did not fare as well as the more established big five personality questionnaires, it did reach adequate levels on each criterion for which it was evaluated. The factor of Extroversion scored the best across the criteria, and Openness to Experience and Agreeableness scored the least well. Overall, the findings suggested that the TIPI should rather be used for research where a very brief measure of a personality scale is required (Muck et al., 2007).
To expand on their study of the TIPI, Gosling et al. (2003) examined the convergent and discriminate correlations between the TIPI and the NEO PI-R scale and facet scores. This exercise presented strong convergent correlations between these two questionnaires, ranging from .56 for Openness to .68 for Conscientiousness. In addition, the correlations of the BFI and NEO PI-R were compared. These correlations were then compared with those of the TIPI-BFI and the TIPI-NEO PI-R. It was concluded that although, as expected, the correlations between the BFI and NEO PI-R were stronger, the correlations between the TIPI and the other two established five-factor measures were very similar, with only a few differences. Overall, the findings provided proof of the construct validity of the TIPI.

In the wake of these studies on the TIPI, more research has been done on this questionnaire in the last few years. Muck et al. (2007) developed a German version of the TIPI (TIPI-G). The factor structure, convergent and discriminant validity, and the correlations of a German version of the adapted NEO PI-R were investigated. The results showed that the five factors of the TIPI-G can provide a satisfactory representation of the big five factors of longer versions of the five-factor trait model. However, as these questionnaires did not measure all the facets of the big five, the use of the TIPI-G was recommended only when time was limited.

The central benefit of the TIPI is that it extends the scope of studies in which the big five personality factors can be measured. Another advantage of the TIPI, as described by Gosling et al. (2003), is that it is a standard questionnaire that can be used by all researchers. Through the use of a standard questionnaire, psychometric properties and external correlates are improved, which will assist other researchers in further studies. Secondly, as the TIPI is a brief measure, it will eliminate item redundancy and reduce participant boredom and frustration (Gosling et al., 2003). In a study performed by Muck et al. (2007), it was established that the TIPI has psychometric properties and measurement categories suitable for use in cross-cultural research.

Whilst the results of the studies of the TIPI indicate that the measure contributes to the base of knowledge of the fivefactor trait model, the message from researchers that this inventory should only be used when time is limited is very clear. Ehrhart et al. (2009) were also concerned with the alpha reliability coefficients of the study they performed using the TIPI and 50 items from the International Personality Item Pool (IPIP), which also measures the FFM. However, Gosling responds that the TIPI was not designed to meet high standards of reliability or other psychometric properties, but rather to create a brief version of the five-factor trait model of personality without sacrificing validity (Ehrhart et al., 2009).

The properties of the BTI and TIPI both show a satisfactory representation of long and short personality questionnaires. Current research on these recently developed questionnaires is quite limited. By evaluating the construct validity of the TIPI the South African-developed BTI, further evidence of 
the measurement of the big five personality factors can be identified.

\section{The present study}

The question of whether or not short personality questionnaires are as reliable and valid as longer personality questionnaires clearly requires further investigation. To this end, the construct validity of a long and a short personality questionnaire will be examined. Construct validity was acknowledged in an article by Lounsbury, Levy, Park, Gibson and Smith (2009) as embracing almost all forms of validity evidence. It is defined as showing the correlation between a construct (conceptual definition of a variable) and the operational procedure to measure that construct ( $\mathrm{O}^{\prime}$ LearyKelly \& Vokurka, 1998). In other words, by evaluating the construct validity of a short personality questionnaire, one is able to determine how well it measures the constructs it is supposed to measure in comparison to a longer personality questionnaire.

The construct validity of the BTI and the TIPI will be examined in this study. The BTI was developed in South Africa by Taylor and De Bruin (2006) for the South African context. This questionnaire can be completed in 45 minutes and is considered to be a long personality questionnaire. The TIPI is a much shorter personality questionnaire and takes about one minute to complete. This questionnaire was developed by Gosling et al. (2003) when the need for a reliable short personality questionnaire was realised. The TIPI is therefore regarded as a short personality questionnaire. The TIPI and the BTI have both developed on the basis of the five-factor trait model, and so both measure the big five personality factors.

\section{Research design Research approach}

This research followed a quantitative research design that examined and compared the construct validity of two personality questionnaires. Primary data was analysed through factor analysis to ascertain if a measure correlated highly with variables with which it should theoretically correlate (convergent validity), but also that it did not correlate significantly with variables from which it should differ (discriminant validity) (Murphy \& Davidshofer, 1998).

\section{Research method}

\section{Research participants}

A convenience sample of 662 undergraduate university students from a university in the Gauteng province, South Africa was used for this study. Participants were; $80 \%$ female, with a mean age of 20.89 years with a standard deviation of 4.83 . In terms of race, white people $(n=412)$ were most represented group in the sample, with fewer African people $(n=114)$, Asian people $(n=81)$ and people of mixed-race $(n=46)$. Nine participants did not indicate their race.

\section{Measuring instruments}

The instruments used were the, BTI and the TIPI personality questionnaires. As the details of these questionnaires have been discussed above; this section will focus on the administration, scoring, reliability and validity of the questionnaires. A biographical questionnaire was administered at the beginning of the testing session to ascertained the age, gender, home language and race of the respondents. This information could be of use in further research.

The BTI currently has 193 items, each in the form of a statement grouped under each of the five factors mentioned. The social desirability scale (consisting of 13 items) is placed between facets throughout the test. The BTI is presented as a single list of items. The items do not appear randomly, but instead are grouped according to their respective facets; further grouped for each factor. This format assists the respondents to better understand and contextualise the statements. There is no formal differentiation between a factor and a facet (Taylor \& De Bruin, 2006).

Respondents are required to indicate to what degree they agree with a particular statement. Items are rated on a fivepoint Likert scale, with possible responses ranging from 1 (strongly disagree) to 5 (strongly agree). The BTI in this study was available in hard copy, and could be completed in either English or Afrikaans (Taylor \& De Bruin, 2006).

The internal consistency reliability coefficients were calculated for each of the factors and facets. The reliability coefficients for the total samples were satisfactory for all the big five personality factors: Extroversion $(\alpha=0.87)$, Neuroticism $(\alpha=0.92)$, Conscientiousness $(\alpha=0.93)$, Openness to Experience $(\alpha=0.87)$ and Agreeableness $(\alpha=0.89)$. With the exception of Openness to Values $(\alpha=0.44)$ and Modesty ( $\alpha=$ $0.56)$, the facets also had acceptable reliabilities (Taylor \& De Bruin, 2006).

Interestingly, the factor analysis conducted on the BTI showed that each of the facets had a primary salient loading on the factor that they were supposed to measure, apart from Straightforwardness, which was the only facet with a secondary loading of 0.312 on Conscientiousness (See Taylor \& De Bruin, 2006, for further information).

The TIPI uses a seven-point Likert scale ranging from 1 (disagree strongly) to 7 (agree strongly). There are ten items, with two descriptors per factor. Participants respond to each item by using the common stem 'I see myself as ...'. Each item has two desirable descriptors and two undesirable descriptors (e.g., for Extroversion, 'Extroverted, enthusiastic' and 'Reserved, quiet') (Woods \& Hampson, 2005). The TIPI takes about one minute to complete (Gosling et al., 2003).

The psychometric properties of the TIPI can be illustrated from the scores of the correlations, test-retest reliability, and external correlates from the study by Gosling et al. (2003). 
According to Gosling et al., the convergent correlations (mean $r=.77$ ) exceeded the discriminant correlations (absolute mean $r=.20$ ), and none of the discriminant correlations exceeded .36. From this result it could be inferred that the TIPI measures the five factors that it claims to measure. Testretest reliability was calculated by correlating the scores obtained in a first rating session with those obtained in a testing session completed six weeks later, and resulted in a score of $r=.72$.

\section{Research procedure}

Questionnaires were administered fairly, and all respondents received the same instructions and time limit within which to complete the questionnaires. Participation was voluntary, and the reason for the study was fully explained to the students before they were asked to complete the questionnaires. Ethical clearance was obtained from the institution to collect data from students. Confidentiality was adhered to, with adequate provisions made to protect the privacy of subjects and to maintain the confidentiality of the data.

The questionnaires were administered in hard copy and were completed during a lecture session. Completion of the questionnaire was conducted during lecture time for teaching purposes. A biographical questionnaire was administered first, followed by the two personality questionnaires. Completion of the questionnaires was carried out under standardised conditions and in accordance with the test publisher's instructions. All the material and answer sheets were collected after the two questionnaires were completed. It was essential that all questions were answered so that the scoring process could be completed. An administrator therefore ensured that all answers were correctly marked on the answer sheet and that no items were omitted. The answer sheets were then numbered and loaded onto an SPSS data sheet and various statistical analyses were performed to obtain factors and correlations.

\section{Statistical analysis}

Exploratory factor analysis (EFA) was conducted to examine the relationship between the BTI and TIPI constructs. First we assessed the dimensionality of the scales and items, in other words, the homogeneity of items. A measure is considered unidimensional when it has statistical properties demonstrating that its items underlie a single construct or factor. When the items are multidimensional, they tap more than one dimension or factor (Netemeyer, Bearden \& Sharma, 2003). This approach assists in gaining insights into which factors should be retained, extracted or rotated in order to interpret the factor structure of the measures (Cohen \& Swerdlik, 2010).

The multitrait-multimethod matrix is another way of establishing validity, and was used in this study. This technique assesses the construct validity of a scale. Cohen and Swerdlik (2010) noted that the construct validity of a test tending to correlate highly in the predicted direction with scores on an older, more established, and already validated, test designed to measure the same or similar construct provides evidence of convergence. Convergent evidence occurs when there are correlations between tests measuring an identical construct, and when there are correlations with a test claiming to measure related constructs. Conversely, discriminate evidence will occur if the test scores or variables do not correlate. At least two attributes, each measured by at least two methods, are required to examine discriminant validity. This data will then form a multitraitmultimethod matrix (Nunnally \& Bernstein, 1994). For this study, a multitrait-multimethod matrix was implemented using the SPSS statistical programme for the five traits (Extroversion, Neuroticism, Conscientiousness, Openness and Agreeableness) that were measured using the two measuring instruments, the BTI and the TIPI.

\section{Results \\ Descriptive statistics}

The means, standard deviations, skewness, kurtosis and Cronbach's alpha coefficients of the BTI facets, the big five personality scales and the TIPI Big Five personality scales are illustrated in Table 1. Although there is evidence of skewness and kurtosis in some of the variable distributions, none of these values was extreme (the skewness coefficients ranged from -0.811 to 0.397 and the kurtosis coefficients ranged from -0.569 to 1.747$)$. Visual inspection of individual histograms confirmed the suitability of the data for factor analysis. The reliabilities of the BTI big five personality scales ranged from 0.90 (Agreeableness) to 0.95 (Neuroticism), and the reliabilities of the BTI facets ranged from 0.68 (Straightforwardness) to 0.89 (Order). Overall, these reliabilities are satisfactory. By contrast, the reliabilities of the TIPI scales were much lower, as expected, given that they consisted of only two items each, and ranged from 0.22 (Agreeableness) to 0.69 (Extroversion). Overall, these reliabilities are unsatisfactory, possibly due to reliability calculations dependent on the number of items used per construct.

\section{Cross-battery correlations of the big five personality traits}

The cross-battery correlations of the TIPI scale scores and the BTI facet and scale scores are summarised in Table 2 (the full correlation matrix, which includes the within-battery correlations, can be obtained from the authors on request). The correlations between the big five personality scale scores of the two batteries were as follows (correlations corrected for attenuation are given in parentheses): Extroversion, $r=0.581$ (0.738); Neuroticism, $r=-0.588$ (-0.883); Conscientiousness, $r=0.593$ (0.868); Openness to Experience, $r=0.520$ (0.837); Agreeableness, $r=0.310$ (0.695).

Closer inspection of Table 2 shows that each of the BTI big five personality traits correlated most strongly with the corresponding TIPI big five personality traits (for instance, the row containing the correlations of the BTI Extroversion scale shows that its strongest correlation with a non-corresponding 
TABLE 1: Descriptive statistics of the BTI and TIPI scales and facets.

\begin{tabular}{lccccc}
\hline Scales and Facets & $\boldsymbol{\alpha}$ & $\mathbf{M}$ & SD & Skewness & Kurtosis \\
\hline Ascendance & 0.81 & 23.081 & 5.102 & -0.005 & -0.218 \\
\hline Liveliness & 0.74 & 27.392 & 5.219 & -0.130 & -0.019 \\
\hline Positive Affect & 0.80 & 22.154 & 4.067 & -0.351 & 0.095 \\
\hline Gregariousness & 0.87 & 25.894 & 5.563 & -0.620 & 0.367 \\
\hline Excitement-seeking & 0.85 & 22.180 & 6.575 & 0.294 & -0.375 \\
\hline Affective Instability & 0.87 & 21.516 & 6.731 & 0.348 & -0.172 \\
\hline Depression & 0.88 & 23.023 & 7.631 & 0.397 & -0.316 \\
\hline Self-consciousness & 0.88 & 27.326 & 7.290 & -0.013 & -0.288 \\
\hline Anxiety & 0.89 & 22.596 & 6.979 & 0.033 & -0.470 \\
\hline Effort & 0.87 & 27.680 & 5.974 & -0.137 & -0.137 \\
\hline Order & 0.89 & 36.026 & 7.482 & -0.176 & -0.214 \\
\hline Dutifulness & 0.82 & 34.902 & 5.011 & -0.203 & 0.139 \\
\hline Prudence & 0.78 & 22.459 & 3.915 & -0.313 & 0.205 \\
\hline Self-discipline & 0.82 & 26.986 & 5.383 & -0.126 & 0.115 \\
\hline Aesthetics & 0.88 & 26.439 & 5.972 & -0.579 & 0.009 \\
\hline Ideas & 0.77 & 21.833 & 4.090 & -0.344 & 0.334 \\
\hline Actions & 0.78 & 25.796 & 4.574 & -0.446 & 0.540 \\
\hline Values & 0.61 & 22.903 & 3.765 & -0.788 & 1.442 \\
\hline Imagination & 0.87 & 23.157 & 4.571 & -0.408 & -0.131 \\
\hline Straightforwardness & 0.68 & 23.997 & 4.297 & -0.198 & 0.335 \\
\hline Compliance & 0.76 & 28.335 & 5.103 & -0.272 & 0.478 \\
\hline Pro-social & 0.79 & 27.949 & 5.188 & -0.147 & 0.039 \\
\hline Modesty & 0.70 & 24.152 & 4.143 & 0.041 & 0.347 \\
\hline Tendermindedness & 0.83 & 28.063 & 4.353 & -0.811 & 1.747 \\
\hline BTI Extroversion & 0.90 & 120.635 & 18.466 & -0.128 & 0.051 \\
\hline BTI Neuroticism & 0.95 & 94.326 & 23.880 & 0.042 & -0.221 \\
\hline BTI Conscientiousness & 0.94 & 148.053 & 21.636 & 0.006 & -0.285 \\
\hline BTI Openness & 0.91 & 120.128 & 16.796 & -0.519 & 0.967 \\
\hline BTI Agreeableness & 0.90 & 132.496 & 16.983 & -0.240 & 1.313 \\
\hline TIPI Extroversion & 0.69 & 9.908 & 3.207 & -0.552 & -0.569 \\
\hline TIPI Agreeableness & 0.22 & 10.378 & 2.225 & -0.288 & -0.304 \\
\hline TIPI Conscientiousness & 0.50 & 11.120 & 2.512 & -0.689 & -0.473 \\
\hline TIPI Neuroticism & 0.47 & 9.595 & 2.733 & -0.381 & -0.494 \\
\hline apenness & 0.923 & 2.286 & -0.794 & 0.280 \\
\hline
\end{tabular}

$\alpha$, alpha; M, mean; SD, standard deviation; BTI, Basic Traits Inventory; TIPI, Ten-Item Personality Inventory.

TIPI scale was 0.319 , which is noticeably lower than its correlation of 0.581 with the corresponding TIPI Extroversion scale). Similarly, each of the TIPI big five personality traits correlated most strongly with the corresponding BTI big five personality scale (for instance, the column containing the correlations of the TIPI Extroversion scale shows that the strongest correlation with a non-corresponding BTI big five personality scale was -0.235 , which is noticeably lower than its correlation of 0.581 with the corresponding BTI Extroversion scale). This pattern of correlations provides support for the convergent and discriminant validity of the scales measured by the two batteries.

\section{Correlations of the BTI facets with the TIPI big five personality traits}

Each of the TIPI big five personality scales correlated significantly with the corresponding BTI facets. The strongest correlations between each of the TIPI big five personality scales and the corresponding BTI facets were as follows: TIPI Extroversion with BTI Gregariousness $(r=0.561)$, TIPI Neuroticism with BTI Affective Instability $(r=-0.579)$, TIPI Conscientiousness with BTI Order $(r=0.575)$, TIPI Openness to Experience with BTI Imagination $(r=0.562)$ and TIPI
TABLE 2: Cross-battery correlations of the BTI and the TIPI.

\begin{tabular}{|c|c|c|c|c|c|}
\hline BTI & TIPI E & TIPI N & TIPI C & TIPIO & TIPI A \\
\hline Extroversion & 0.581 & 0.159 & -0.059 & 0.319 & -0.052 \\
\hline Ascendance & 0.493 & 0.082 & 0.038 & 0.221 & -0.127 \\
\hline Liveliness & 0.412 & 0.098 & 0.051 & 0.191 & -0.015 \\
\hline Positive affectivity & 0.304 & 0.289 & 0.100 & 0.202 & 0.171 \\
\hline Gregariousness & 0.561 & 0.127 & -0.055 & 0.237 & 0.033 \\
\hline Excitement-seeking & 0.260 & 0.021 & -0.253 & 0.254 & -0.166 \\
\hline Neuroticism & -0.235 & -0.588 & -0.111 & -0.216 & -0.147 \\
\hline Affective instability & -0.092 & -0.579 & -0.103 & -0.116 & -0.266 \\
\hline Depression & -0.242 & -0.497 & -0.150 & -0.146 & -0.149 \\
\hline Self-consciousness & -0.286 & -0.414 & -0.085 & -0.247 & -0.068 \\
\hline Anxiety & -0.149 & -0.477 & -0.029 & -0.198 & -0.007 \\
\hline Conscientiousness & -0.003 & 0.115 & 0.593 & 0.036 & 0.107 \\
\hline Effort & 0.068 & 0.089 & 0.398 & 0.084 & 0.090 \\
\hline Order & -0.050 & 0.077 & 0.575 & -0.061 & 0.068 \\
\hline Dutifulness & -0.013 & 0.084 & 0.393 & 0.032 & 0.151 \\
\hline Prudence & -0.005 & 0.047 & 0.386 & 0.087 & -0.008 \\
\hline Self-discipline & -0.003 & 0.144 & 0.495 & 0.043 & 0.102 \\
\hline Openness to experience & 0.187 & 0.047 & -0.026 & 0.520 & -0.003 \\
\hline Aesthetics & 0.041 & 0.039 & -0.001 & 0.304 & 0.023 \\
\hline Ideas & 0.152 & 0.041 & -0.036 & 0.358 & -0.012 \\
\hline Actions & 0.297 & 0.090 & -0.006 & 0.476 & 0.008 \\
\hline Values & 0.035 & -0.028 & -0.022 & 0.190 & -0.020 \\
\hline Imagination & 0.174 & 0.017 & -0.040 & 0.562 & -0.020 \\
\hline Agreeableness & 0.077 & 0.050 & 0.126 & 0.165 & 0.310 \\
\hline Straightforwardness & 0.136 & 0.076 & 0.155 & 0.079 & 0.248 \\
\hline Compliance & 0.032 & 0.028 & 0.063 & 0.037 & 0.311 \\
\hline Prosocial tendencies & 0.104 & 0.010 & 0.020 & 0.172 & 0.135 \\
\hline Modesty & -0.111 & 0.067 & 0.083 & 0.122 & 0.191 \\
\hline Tendermindedness & 0.110 & 0.012 & 0.161 & 0.201 & 0.257 \\
\hline
\end{tabular}

BTI, Basic Traits Inventory; A, Agreeableness; C, Conscientiousness; E, Extraversion; N, Neuroticism; O, Openness; TIPI, Ten-Item Personality Inventory.

All correlations are rounded to three decimal places. Correlations between corresponding big five personality scales of the two batteries are printed in bold. The highest correlation in each of the remaining rows is printed in italics.

Agreeableness with BTI Compliance $(r=0.311)$. The multiple correlations of each TIPI big five personality scale with the corresponding set of BTI facets were as follows: Extroversion, $R=0.630$; Neuroticism, $R=0.625$; Conscientiousness, $R=$ 0.629 ; Openness, $R=0.612$; Agreeableness, $R=0.343$.

\section{Factor analysis of the BTI facets and the TIPI}

A joint principal axis factor analysis of the BTI facets and the TIPI big five personality scales provided further insight into the discriminant and convergent validity of the traits measured by the two batteries. The Kaiser-Meyer-Olkin measure of sampling adequacy was 0.856 , confirming that the correlations between the variables were suitable for factor analysis (Kaiser, 1970). The scree-plot of the eigenvalues (see Figure 1), a parallel analysis (see Figure 1) and inspection of the correlation residuals suggested that the five factors should be retained, which corresponded with the theoretical model underlying the two batteries. The five-factor solution was obliquely rotated according to the direct quartimin criterion, and the resulting factor pattern matrix is given in Table 3.

The rotated factor pattern matrix corresponded very strongly with theoretical expectations: each of the five factors was defined by one TIPI big five personality scale and the 
corresponding BTI facets (see Table 3). The pattern matrix showed that factor 1 may be labelled as Extroversion, factor 2 as Neuroticism, factor 3 as Conscientiousness, factor 4 as Agreeableness and factor 5 as Openness to Experience. All the BTI facets and the TIPI scales were most strongly loaded by their expected factors, and no facet or scale was strongly loaded by unexpected factors (note, however, that Positive Affect did have a marginally salient coefficient pattern of 0.312 on the Agreeableness factor). This evidence shows that all the variables included in the analysis measured their intended factors, and none of the variables measured unintended factors.

The correlations between the five factors are given in Table 4. The largest correlation was between Extroversion and Openness to Experience $(r=0.368)$. With most of the correlations close to zero, it can be concluded that the factors are indeed independent of each other.

\section{Discussion}

This study had one main objective, examining the construct validity of the BTI and the TIPI to evaluate if they measure the five-factor personality traits as theoretically presented. The first step was to determine the convergent and discriminant validity of the TIPI and BTI. The results showed support for convergent and discriminant validity of the scales measured by the BTI and TIPI. The correlations between the big five personality scores of the two batteries were satisfactory, except for Agreeableness. Interestingly, this low correlation in respect for Agreeableness is similar to what emerged in the study by Ehrhart et al. (2009), in which they investigated the effectiveness of the use of a short personality questionnaire and a cross-cultural personality questionnaire. The aim of their study was to further assess the psychometric properties of the TIPI across diverse ethnic groups, taking into consideration how the test may provide insight if used with samples where ethnic groups are in minority. The findings showed encouraging results with regard to four factors within the five-factor model, with the items loading strongly on their respective factors, with the exception of Agreeableness, which had a loading of .31. It was suggested that this factor scored low because of differences in interpretation of Openness and Intellect/Imagination.

Furthermore, in the study performed by Gosling et al. (2003), Extroversion scored the highest across the criteria, and Agreeableness and Openness to Experience fared least well. Although further investigation of validity of the measure of Agreeableness is needed, the analysis suggests that the TIPI can provide a satisfactory measure of the five-factor trait model of personality constructs. It can be concluded that there is a high degree of convergence between the big five personality factors that underlie the TIPI and those that underlie the BTI.

As already mentioned, according to Friedenberg (1995), reliability is one of the psychometric properties that

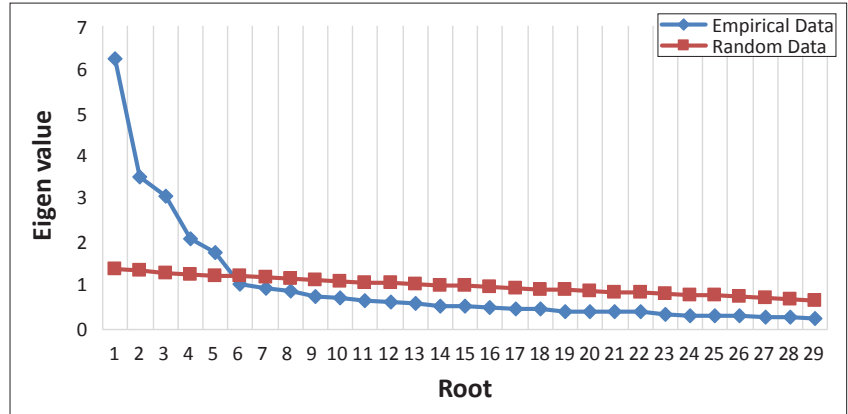

FIGURE 1: The scree and parallel analysis plot.

TABLE 3: Direct quartimin rotated factor pattern matrix of the BTI facets and TIPI scales.

\begin{tabular}{lccccc}
\hline Variable & \multicolumn{5}{c}{ Factor } \\
\cline { 2 - 6 } & $\mathbf{1}$ & $\mathbf{2}$ & $\mathbf{3}$ & $\mathbf{4}$ & $\mathbf{5}$ \\
\hline BTI Extroversion & - & - & - & - & - \\
Ascendance & 0.635 & - & - & - & - \\
Liveliness & 0.657 & - & - & - & - \\
Positive affect & 0.363 & - & - & 0.312 & - \\
Gregariousness & 0.718 & - & - & - & - \\
Excitement-seeking & 0.401 & - & - & - & - \\
BTI Neuroticism & - & - & - & - & - \\
Affective instability & - & 0.784 & - & - & - \\
Depression & - & 0.782 & - & - & - \\
Self-consciousness & - & 0.712 & - & - & - \\
Anxiety & - & 0.741 & - & - & - \\
BTI Conscientiousness & - & - & - & - & - \\
Effort & - & - & 0.666 & - & - \\
Order & - & - & 0.750 & - & - \\
Dutifulness & - & - & - & - & 0.564 \\
\hline Prudence & - & - & 0.605 & - & - \\
Self-discipline & - & - & 0.743 & - & - \\
BTI Openness & - & - & - & - & - \\
Aesthetics & - & - & 0.732 & - & - \\
Ideas & - & - & - & - & - \\
Actions & - & - & - & - & 0.637 \\
Values & - & - & - & - & 0.675 \\
Imagination & - & - & - & - & 0.530 \\
BTI Agreeableness & - & - & - & - & 0.458 \\
Straightforwardness & - & - & - & - & 0.778 \\
Compliance & - & - & - & - & - \\
Pro-social & - & - & - & 0.448 & - \\
Modesty & - & - & - & 0.513 & - \\
Tendermindedness & - & - & - & - \\
TIPI scales & - & - & - & - \\
TIPI Extroversion & - & - & - & - \\
TIPI Agreeableness & - & - & - & - \\
TIPI Conscientiousness & - & - & - & - \\
TIPI Neuroticism & - & - & - & - \\
\hline TIPI Openness & - & - & - & - \\
\hline BTI, Basic Trits & - & - & - & - \\
\hline
\end{tabular}

BTI, Basic Traits Inventory; TIPI, Ten-Item Personality Inventory.

Factor pattern coefficients are rounded to three decimal places. To facilitate interpretation, factor pattern coefficients $<|0.30|$ are omitted. The full pattern matrix is available from the first author upon request.

TABLE 4: Factor correlation matrix

\begin{tabular}{lccccc}
\hline Personality factor & $\mathbf{1}$ & $\mathbf{2}$ & $\mathbf{3}$ & $\mathbf{4}$ & $\mathbf{5}$ \\
\hline 1. Extroversion & 1.000 & -0.170 & 0.064 & 0.077 & 0.368 \\
2. Neuroticism & -0.170 & 1.000 & -0.094 & -0.067 & -0.040 \\
3. Conscientiousness & 0.064 & -0.094 & 1.000 & 0.293 & 0.115 \\
4. Agreeableness & 0.077 & -0.067 & 0.293 & 1.000 & 0.247 \\
5. Openness & 0.368 & 0.040 & 0.115 & 0.247 & 1.000 \\
\hline
\end{tabular}


determine if a questionnaire is an effective test. The reliability coefficients of the BTI were satisfactory. These results imply that if the questionnaire is completed again by the same population group, the results will be consistent with the first attempt. Overall, the reliability scores of the TIPI were unsatisfactory. As this questionnaire only consists of two items per factor, it was expected that the TIPI would have lower reliability scores than the BTI. The result for the TIPI may pose concerns in terms of adherence to the requirements of South Africa's Employment Equity Act.

The next step was to determine the correlations of the BTI facets with the TIPI big five personality factors in order to establish whether the TIPI measured the same factors as the BTI. Overall, as shown by the convergent validity correlations, each TIPI scale correlated substantially with the relevant BTI facet scales. The study yielded convergent correlations that exceeded the discriminant correlations. Inspection of the rotated pattern matrix showed that each item demonstrated convergent and discriminant validity in that each item had a salient loading on its theoretically intended factor and nonsalient loadings on all the other factors.

The factor loadings on the items were relatively strong, with the exception of Extroversion and Openness to Experience. The strongest correlation of the TIPI Extroversion and the facets from the BTI were with Ascendance, Liveliness and Gregariousness. However, it is important to note that the Positive Affect BTI trait correlated on both Extroversion and Agreeableness. Although the correlation was low on both traits, the Positive Affect trait should be further explored in future studies.

All the facets of BTI Neuroticism and Conscientiousness correlated highly with TIPI Neuroticism and Conscientiousness respectively. In terms of the BTI, the facets of Openness to Experience had satisfactory ratings, with Imagination and Ideas scoring the highest correlations. The facets in the BTI Agreeableness were also satisfactory, with the Compliance facet correlating highly with the Agreeableness trait of the TIPI. Each trait appears to be unidimensional, which allows for unequivocal interpretation (with the exception of the BTI Positive Affect). The results suggest that the TIPI factors serve as good indicators of the respective BTI facets. In a similar research study, it was suggested that the TIPI short personality questionnaire should be the questionnaire of choice instead of the 44-Item BFI or the 60item NEO-FFI. It was determined that the 44-item BFI and the 60-item NEO-FFI did not provide satisfactory facet scores for the big five personality factors when compared to the TIPI (Gosling et al., 2003).

Overall, the results of the factor analysis provided strong support for the construct validity of the two personality inventories. Whilst the results lend support that there is clear fit of the two tests with the five-factor model in terms of convergent validity. The Cronbach's alpha coefficients of the TIPI factors ranged from 0.22 to 0.69 and were much lower than the BTI factors, which ranged from 0.90 to 0.95 . These low reliabilities may reflect a degree of measurement error, and it is therefore recommended that the TIPI should be used when time is limited and only when a short measure of the big five personality factors will suffice. Conversely, the BTI showed satisfactory convergent and discriminate validity and can be regarded as a suitable measure of elements of the five-factor trait model.

\section{Research limitations}

This study has two limitations. The first is that the participants were mainly students. It is not clear if the results would be in a different participant sample, but if the questionnaire is to be used across the population spectrum, it is important that the study be replicated across a wider, more representative South African sample. The second limitation was that this study did not further investigate the low correlations found in the Agreeableness factor. More specific measurement and analysis of this factor will no doubt provide more clarity in this study and those by other studies (Ehrhart et al., 2009; Gosling et al., 2003).

\section{Recommendations and conclusions}

Currently, in the field of psychological assessment, good psychometric properties and the use of quick and efficient assessments need to be balanced. This study focused on revising and broadening the current knowledge of the TIPI and the BTI in an attempt to provide information on the appropriateness of using short or long personality questionnaires. It may be said with confidence that the TIPI will prove useful to researchers who wish to investigate personality at a theoretical level and when time is of the essence. The TIPI can also be used to create opportunities for research purposes, and to encourage researchers to design new studies based on the FFM model. The TIPI will help researchers to measure the big five personality factors in a simpler, quicker and more efficient manner. It has been shown that, when a longer personality questionnaire is required, the BTI is a very good measure of the five-factor personality traits, with the facets clearly defined to measure the big five personality factors. Although the five factors retained satisfactory correlations when comparing the TIPI and the BTI, the general recommendation is that the TIPI should not replace the longer BTI personality questionnaire. Due to the unsatisfactory reliability results of the TIPI, this questionnaire should rather be used when time is short or when multiple methods of assessment are required from a respondent in a short space of time.

\section{Acknowledgements Competing interests}

The authors declare that they have no financial or personal relationship(s) that may have inappropriately influenced them in writing this article.

\section{Authors' contributions}

S.M. (University of Johannesburg) was the master's student on whose work this article is based. G.P.D. (University of 
Johannesburg) was the main supervisor and conceptualised the study. B.G.A. (University of Johannesburg) was the cosupervisor, and prepared the manuscript for publication.

\section{References}

Anastasi, A., \& Urbina, S. (1997). Psychological testing. (7th edn.). New Jersey: Prentice Hall.

Burisch, M. (1997). Test length and validity revisited. European Journal of Psychology, $11,303-315$.

Cohen, R.J., \& Swerdlik, M.E. (2010). Psychological testing and assessment: An introduction to tests and measurement. Boston, MA: McGraw-Hill.

Costa, P.T. (2008). Work and personality: Use of the NEO-PI-R in Industrial/ Organisational Psychology. Applied Psychology, 45, 225-241. http://dx.doi. org/10.1111/j.1464-0597.1996.tb00766.x

Ehrhart, M.G., Ehrhart, K.H., Roesch, S.C., Chung-Herrera, B.G., Nadler, K., \& Bradshaw K. (2009). Testing the latent factor structure and construct validity of the ten-item personality inventory. Personality and Individual Differences, 47, 900-905. http:// dx.doi.org/10.1016/j.paid.2009.07.012

Friedenberg, L. (1995). Psychological testing: Design, analysis and use. Boston, MA: Allyn \& Bacon.

Gosling, S.D., Rentfrow, P.J., \& Swann, W.B. Jr. (2003). A very brief measure of the Big Five personality factors personality domains. Journal of Research in Personality, 37, 504-528. http://dx.doi.org/10.1016/S0092-6566(03)00046-1

Hofmans, J., Kuppens, P., \& Allik, J. (2008). Is short in length short in content? An examination of the domain representation of the ten-item personality inventory scales in Dutch language. Personality and Individual Differences, 45, 750-755. http://dx.doi.org/10.1016/j.paid.2008.08.004

Kaiser, H. (1970) A second generation little jiffy. Psychometrika. 35, 401-415. http:// dx.doi.org/10.1007/BF02291817

Laher, S. (2007). Personality reconceptualised: A Millonian approach? SA Journal of Industrial Psychology, 37(1), 82-95.

Lounsbury, J.W., Levy, J.J., Park, S., Gibson, L.W., \& Smith, R. (2009). An investigation of the construct validity of the personality trait of self-directed learning. Learning and Individual Differences, 19(4), 411-418. http://dx.doi.org/10.1016/j. lindif.2009.03.001

McCrae, R.R., \& Allik, J. (2002). The Five-Factor model of personality across cultures. New York, NY: Kluwer Academic/Plenum Publishers. http://dx.doi. org/10.1007/978-1-4615-0763-5
Meiring, D., Van de Vijver, A.J.R., Rothmann, S., \& Barrick, M.R. (2005). Construct, item, and method bias of cognitive and personality tests in South Africa. SA Journal of Industrial Psychology, 31(1), 1-8. http://dx.doi.org/10.4102/sajip.v31i1.182

Muck, P.M., Hell, B., \& Gosling, S. D. (2007). Construct validation of a short five-factor model assessment: A self-peer study on the German adaptation of the ten-item personality inventory (TIPI-G). European Journal of Psychological Assessment, 23(3), 166-175. http://dx.doi.org/10.1027/1015-5759.23.3.166

Murphy, K.R., \& Davidshofer, C.O. (1998). Psychological testing: Principles and applications. (4th edn.). Engelwood Cliffs, NJ: Prentice Hall.

Netemeyer, R.G., Bearden, W.O., \& Sharma, S. (2003). Scaling procedures: Issues and applications. Thousand Oaks, CA: Sage. PMid:12880188

Nunnally, J.C., \& Bernstein, I.H. (1994). Psychometric theory. (3rd edn.). New York, NY: McGraw-Hill.

O'Leary-Kelly, S.W., \& Vokurka, R.J. (1998). The empirical assessment of construct validity. Journal of Operations Management, 16, 387-405. http://dx.doi. org/10.1016/S0272-6963(98)00020-5

Pervin, L.A., \& John, O.P. (1999). Handbook of personality theory and research. (2nd edn.). New York, NY: Guilford. PMid:10455066

Republic of South Africa. (1998). Government gazette, 400 (19370). Pretoria, South Africa: Government Printer.

Rothman, S., \& Coetzer, E.P. (2002). The relationship between personality dimensions and job satisfaction. Business Dynamics, 11, 29-39.

Salkind, N.J. (2006). Tests and measurements for people who think they hate tests and measurements. California: Sage. PMid:17100034

Saucier, G. (1994). Mini-markers: A brief version of Goldberg's unipolar Big-Five markers. Journal of Personality Assessment, 63, 506-516. http://dx.doi. org/10.1207/s15327752jpa6303_8

Taylor, N. (2004). The construction of a South African five-factor personality inventory. Unpublished master's dissertation. Rand Afrikaans University, Johannesburg, South Africa.

Taylor, N., \& De Bruin, G.P. (2006). BTI. Johannesburg, South Africa: Manual of the Basic Traits Inventory JvR.

Tett, R.P., \& Burnett, D.D. (2003). A personality trait based interactionist model of job performance. Journal of Applied Psychology, 88, 500-517. http://dx.doi. job performance. Journal of Applie
org $10.1037 / 0021-9010.88 .3 .500$

Van Eeden, R., Cilliers, F., \& Van Deventer, V. (2008). Leadership styles and associated personality traits: Support for the conceptualisation of transactional and transformational leadership. SA Journal of Psychology, 38(2), 253-267. http:// dx.doi.org/10.1177/008124630803800201

Woods, S.A., \& Hampson, S.E. (2005). Measuring the Big Five with single items using a bipolar response scale. European Journal of Psychology, 19, 373-390. 